\title{
Chikungunya association with different presentation at tertiary care centre
}

\begin{abstract}
Introduction: Acute viral infection belong to the group of arthropod .Chikungunya fever now a days is spreading worldwide and some recent studies shown the different $t$ features and most clinical features is topic of inertest is bony pain, which is the most severe form . Chikungunya fever is going to be the increasing number in the financially and economical burden.

\section{Methodology}

Sample size: Total number of total patients was 245 in our study.

Study design: Cohort study, systemically all patients were enrolled.

Inclusion criteria: The age group of 14 years to 69 was enrolled. The symptoms and duration and intensity of fever were systemically classified for the study. Only viral fever patients were included.

Exclusion criteria: The age group less than 13 and more than 70 years were excluded. Fever other than viral not included. Known case of any joint deformity and joint disease were excluded. The patients already using different types of painkillers prior to the disease for any systemic disease were not included.

Data entry: SPSS 22 used for data entry.

Result: A total 245 patients with duration of six month were selected for the study. We enrolled patients within six month period time. Total of patients visiting the hospital of age group of 14 age to 60 plus

Conclusion: Fever of the patients were include both low grade and high grade, Most patient were having no symptoms except fever while rest, 38 patients having diarrhea, and 36 patients having vomiting 24 patients had flu like symptoms, flushing in 18 patients noticed and 18 patients having multiple presentations. The duration of the patients with the symptoms last for one week to three months. Most of them responded and get bettered with first 3 weeks and responded to acetaminophen.
\end{abstract}

Keywords: Chikungunya, CHIKV, Viral fever, Joint pain
Volume 5 Issue 7 - 2017

\author{
Sumera Nawaz Qabulio, Muhammad Fahad \\ Zakir, Fasiha Sohail, Ghania Niazi, Muhammad \\ Fahad Zakir \\ Department of Medicine, Ziauddin University and Hospital, \\ Pakistan
}

\author{
Correspondence: Sumera Nawaz Qabulio, Ziauddin University \\ and Hospital, Karachi, Pakistan \\ Co-correspondence: Muhammad Fahad Zakir, Ziauddin \\ University and Hospital, Karachi, Pakistan, \\ Emailfaha_bawani@hotmail.com
}

Received: August 19, 2017 | Published: November 02, 2017

\section{Abbreviations: CHIKV, Chikungunya Virus; VF, viral Fever Introduction}

Acute viral infection belong to the group of anthropode., ${ }^{1,2}$ Chikungunya fever now a days is spreading worldwide and some recent studies shown the different $t$ features and most clinical features is topic of inertest is bony pain, which is the most severe form..$^{3-6} \mathrm{In}$ India the Chikungunya fever is going to be the increasing number in the financially and economical burden. ${ }^{7}$ Dengue and Chikungunya are major worldwide wellbeing worries because of their proceeded with spread and strengthening plague exercises all through a large portion of the tropical and subtropical areas of the world. Consistent flare-ups of dengue have been accounted for all through the majority of the tropical and sub-tropical areas of the world for a very long while ${ }^{8-10}$ while Chikungunya pandemics have accomplished worldwide dispersion inside the previous ten years; yet extensive scale pestilences of dengue fever and Chikungunya fever has just as of late introduced as a developing wonder in Africa. ${ }^{11}$

Tanzania, the same number of other African nations, is encountering a move in illness transmission designs with respect to febrile irresistible maladies. While the quantity of instances of intestinal sickness are diminishing in a few nations of sub-Saharan Africa, ${ }^{12-15}$ the quantity of febrile cases because of different causes than jungle fever are still high. ${ }^{16}$

\section{Research and methodology}

\section{Sample size}

Total number of total patients was 245 in our study.

\section{Study design}

Cohort study, systemically all patients were enrolled .Two investigators assigned for collection of data.

\section{Inclusion criteria}

The age group of 14 years to 69 was enrolled. The symptoms and duration and intensity of fever were systemically classified for the study. The only viral fever patients were included.

\section{Exclusion criteria}

The age group less than 13 and more than 70 years were excluded. Fever other than viral not included. Known case of any joint deformity 
and joint disease were excluded. The patients already using different types of painkillers prior to the disease for any systemic disease were not included.

Data entry: SPSS 22 used for data entry.

\section{Results}

A total 245 patients with duration of six month were selected for the study. We enrolled patients within six month period time. Total of patients visiting the hospital of age group of 14 age to 60 plus. The frequency of patients with age were classified in the (Figures 1-7).

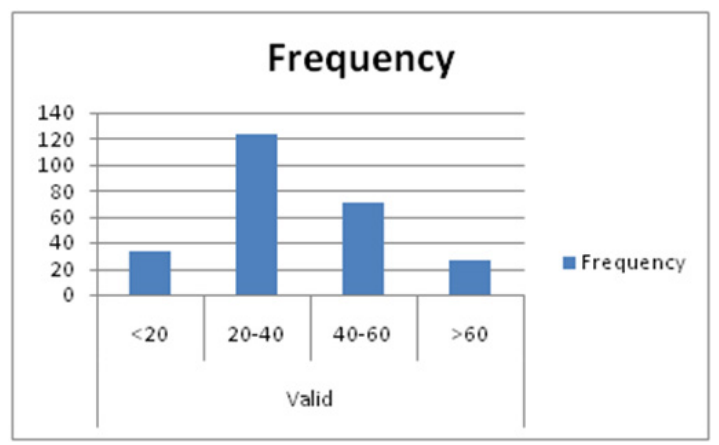

Figure I The Frequency of patients with age.

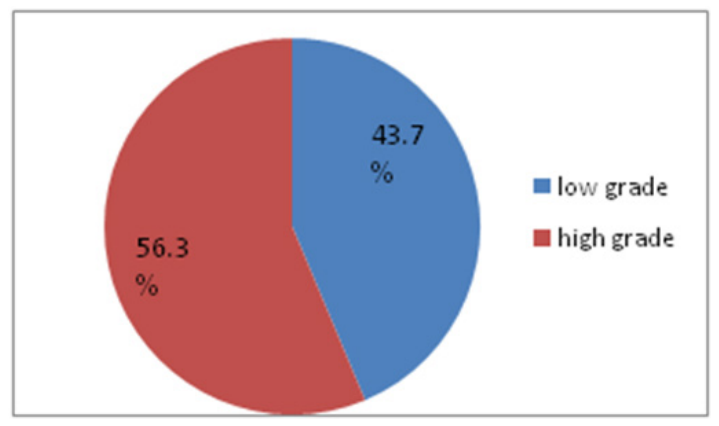

Figure 2 Fever of the patients was including both low grade and high grade .The percentage of the fever almost same that was 56.3 percent of high grade and 43.7 percent having low grade.

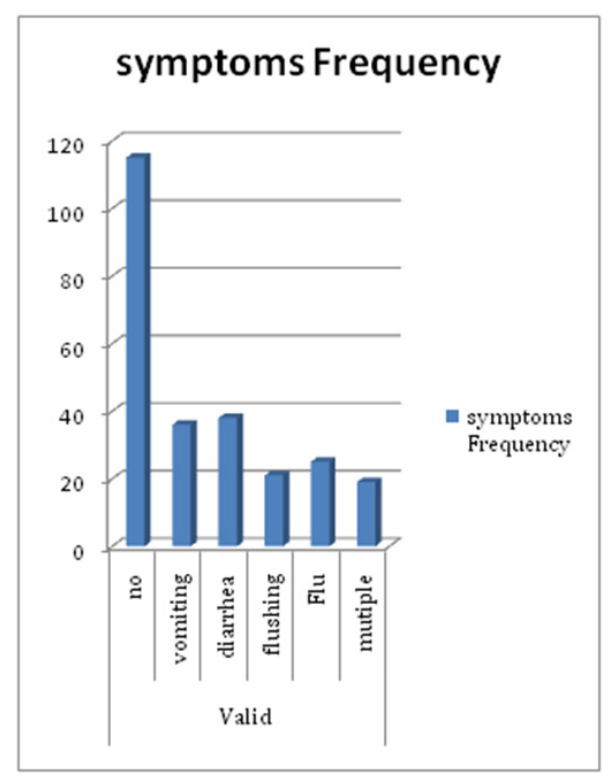

Figure 3 Almost 120 patients were asymptomatic, 38 patients having diarrhea, and 36 patients having vomiting 24 patients having flu like symptoms, flushing in 18 patients and 18 patients having more multiple presentations.

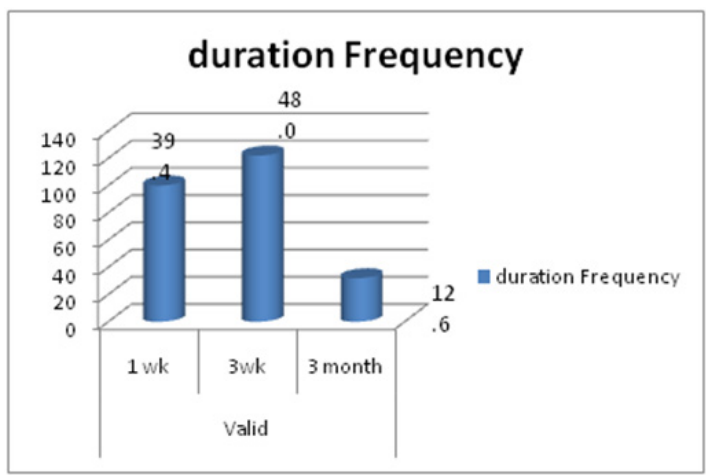

Figure 4 The duration of the patients with the symptoms last for one week to three months. The 39.4 percentage for I week duration, 3 week last for around 48.0 percent of patients and 12.6 percent of patients last for 3 months.

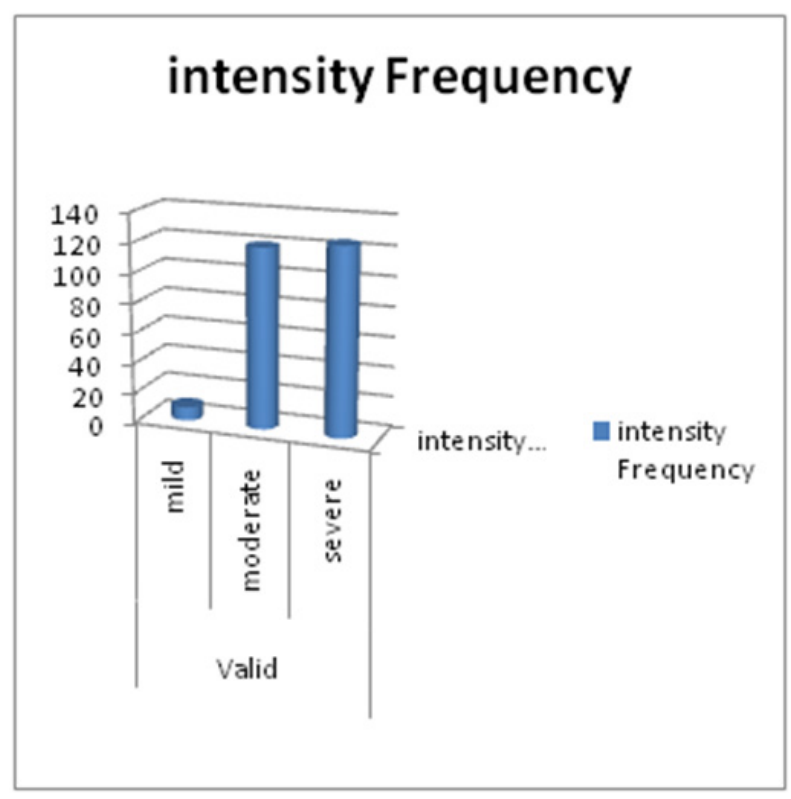

Figure 5 MILD: The symptoms were divided according to the severity mild intensity was around ten patients.

Moderate: The symptoms of moderate severity were found in around 110 patients.

Severe:The symptoms of severe intensity were found around 120 patients.

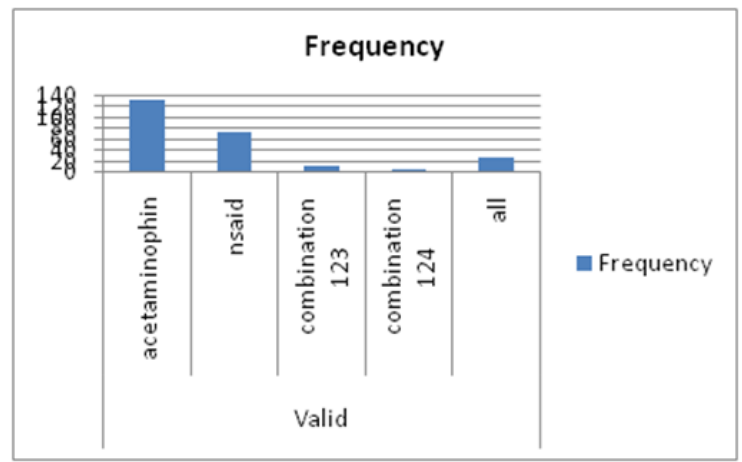

Figure 6 The acetaminophen alone used in 130 patients Nsaid alone used in 78 numbers of patients. Combination of three drugs acetaminophen, Nsaid and steroid were used in 10 numbers of patients and combination of acetaminophen, Nsaid and DMarts in 5 numbers of patients. The combination of all drugs was used in 140 numbers of patients. 


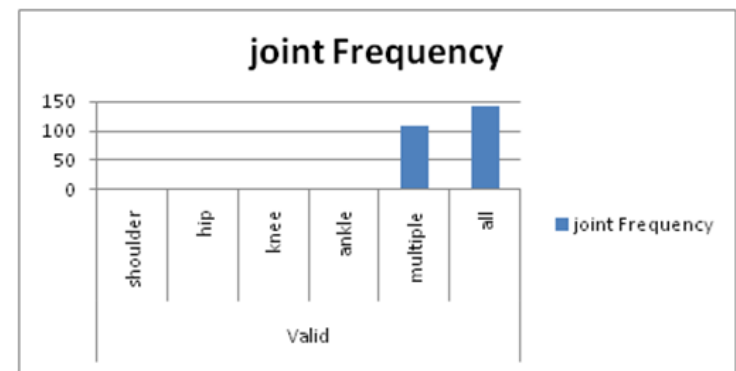

Figure 7

\section{Discussion}

Chikungunya fever is an intense febrile sickness with a brooding time of 3-7 days. It influences all age gatherings and both genders similarly, with an assault (rate of people who create sickness after contamination) of 40\%-85\%]. Different arbovirus are no doubt vital and are increasing more unmistakable quality as seen through an expansion in detailed action ${ }^{17-20}$ ] and plague action of sicknesses, for example, dengue and Chikungunya. ${ }^{21-24} \mathrm{Also}$, intestinal sickness should have been over-analyzed in various parts of Tanzania, ${ }^{25-27}$ mostly because of absence of differential pathogen analysis separated from jungle fever, ${ }^{28}$ including dengue and Chikungunya. Late examinations in Tanzania have uncovered that patients with intense dengue and Chikungunya disease are frequently misdiagnosed and treated with hostile to malarial or anti-microbial..$^{29,30}$ The advancement of medication safe intestinal sickness strains (due to over-recommending of anti malarial. ${ }^{31}$

Patients give sudden onset of high-review fever regularly achieving $102^{\circ}-105^{\circ} \mathrm{F}$, with shaking cools that last 2-3 days. The fever may return for 1-2 days after a febrile time of 4-10 days, subsequently called a "seat back fever. These infections are transmitted between people by the chomp of tainted Aedes aegypti mosquitoes; moreover Chikungunya has expanded its geological range by its capacity to contaminate Aedes albopictus..$^{32,33}$ Most arbovirus contaminations are asymptomatic, ${ }^{34}$ however can too cause an expansive range of indications, extending from nonspecific influenza like disorder to extreme confusions. ${ }^{35-37}$

\section{Conclusion}

Fever of the patients were include both low grade and high grade, Most patient were having no symptoms except fever while rest, 38 patients having diarrhea, and 36 patients having vomiting 24 patients had flu like symptoms, flushing in 18 patients noticed and 18 patients having multiple presentations. The duration of the patients with the symptoms last for one week to three months. Most of them responded and get bettered with first 3 weeks and responded to acetaminophen.

\section{Acknowledgments}

Thanks to Professor Umer Jahangir (Head of Department Medicine) for supporting and helping us in writing and entitling this research article.

\section{Conflicts of Interest}

This study is self funded, there were no financial, socially, economically or moral conflict.

\section{References}

1. Mohan A. Chikungunya fever: clinical manifestations \& management. Indian J Med Res. 2006;124(5):471-474.
2. Mohan A. Chikungunya fever strikes in Andhra Pradesh. Natl Med J India. 2006;19:240.

3. Simon F, Savini H, Parola P. Chikungunya: a paradigm of emergence and globalization of vector-borne diseases. Med Clin North Am. 2008;92(6):1323-1343.

4. Sudeep AB, Parashar D. Chikungunya: an overview. J Biosci. 2008;33(4):443-449.

5. Chevillon C, Briant L, Renaud F, et al. The Chikungunya threat: an ecological and evolutionary perspective. Trends Microbiol. 2008;16(2):80-88.

6. Pialoux G, Gaüzère BA, Jauréguiberry $\mathrm{S}$, et al. Chikungunya, an epidemic arbovirosis. Lancet Infect Dis. 2007;7(5):319-327.

7. Simon F, Savini H, Parola P. Chikungunya: a paradigm of emergence and globalization of vector-borne diseases. Med Clin North Am. 2008;92(6):1323-1343.

8. Pro Med, Dengue/DHF Updates. 2015

9. Health Map, Dengue Epidemic in Brazil. 2015.

10. Wang S, Chang K, Lu R, et al. Large Dengue virus type 1 outbreak in Taiwan. Emerg Microbes Infect. 2015;4(8):e46.

11. Schwarz NG, Girmann M, Randriamampionona N, et al. Seroprevalence of antibodies against chikungunya, dengue, and Rift Valley fever viruses after febrile illness outbreak, Madagascar. Emerg Infect Dis. 2012;18(11):1780-1786.

12. Aregawi MW, Ali AS, Al mafazy A, et al. Reductions in malaria and anaemia case and death burden at hospitals following scale-up of malaria control in Zanzibar, 1999-2008. Malar J. 2011;10:46.

13. O’Meara WP, Mangeni JN, Steketee R, et al. Changes in the burden of malaria in sub-Saharan Africa. Lancet Infect Dis. 2010;10(8):545-555.

14. Ishengoma DS, Mmbando BP, Segeja MD, et al. Declining burden of malaria over two decades in a rural community of Muheza district, north-eastern Tanzania. Malar J Malaria Journal. 2013;12:338

15. Karema C, Aregawi MW, Rukundo A, et al. Trends in malaria cases, hospital admissions and deaths following scale-up of anti-malarial interventions, 2000-2010, Rwanda. Malar J. 2012;11:236.

16. D'Acremont V, Lengeler C, Genton B. Reduction in the proportion of fevers associated with Plasmodium falciparum parasitaemia in Africa: a systematic review. Malar J. 2010;9:240.

17. Awando J, Ongus J, Ouma C, et al. Seroprevalence of Anti-Dengue Virus 2 Serocomplex antibodies in out-patients with fever visiting selected hospitals in rural parts of western Kenya in 2010-2011: A cross sectional study. Pan Afr Med J. 2003;16(73):1-10.

18. Vairo F, Nicastri E, Meschi S, et al. Seroprevalence of dengue infection: a cross-sectional survey in mainland Tanzania and on Pemba Island, Zanzibar. Int J Infect Dis. 2012;16(1):e44-46.

19. Vairo F, Nicastri E, Yussuf SM, et al. IgG Against Dengue Virus in Healthy. Emerg Infect Dis. 2014;20:465-468.

20. Weller N, Clowes P, Dobler G, et al. Seroprevalence of alphavirus antibodies in a cross-sectional study in southwestern Tanzania suggests endemic circulation of chikungunya. PLoS Negl Trop Dis. 2014;8:e2979.

21. Orengo P. State confirms outbreak of dengue fever in Mandera. Stand Digit News Pap. Internet. 2011.

22. Pro Med, Dengue/DHF Updates. 2009.

23. Schwartz E, Meltzer E, Mendelson M, et al. Detection on four continents of dengue fever cases related to an ongoing outbreak in Luanda, Angola , March to May 2013. Euro Surveill. 2013;18(21):pii:20488.

24. WHO, Dengue outbreak in the United Republic of Tanzania (Situation as of 30 May 2014). 
25. Crump JA, Morrissey AB, Nicholson WL, et al. Etiology of severe nonmalaria febrile illness in Northern Tanzania: a prospective cohort study. PLoS Negl Trop Dis. 2013;7(7):e2324.

26. Harchut K, Standley C, Dobson A, et al. Over-diagnosis of malaria by microscopy in the Kilombero Valley, Southern Tanzania: an evaluation of the utility and cost-effectiveness of rapid diagnostic tests. Malar $J$ Malaria J. 2013;12:159.

27. Reyburn H, Mbatia R, Drakeley C, et al. Greenwood BM \& Whitty CJM. Overdiagnosis of malaria in patients with severe febrile illness in Tanzania: a prospective study. BMJ. 2004;329(7476):1212.

28. Chandler CIR, Jones C, Boniface G, et al. Guidelines and mindlines: why do clinical staff over-diagnose malaria in Tanzania? A qualitative study. Malar J. 2008;7:53.

29. Hertz JT, Munishi OM, Ooi EE, et al. Chikungunya and dengue fever among hospitalized febrile patients in northern Tanzania. Am J Trop Med Hyg. 2012;86(1):171-177.

30. Harchut K, Standley C, Dobson A, et al. Over-diagnosis of malaria by microscopy in the Kilombero Valley, Southern Tanzania: an evaluation of the utility and cost-effectiveness of rapid diagnostic tests. Malar $J$ Malaria J. 2013;12:159.
31. Hume JCC, Barnish G, Mangal T, et al. Household cost of malaria overdiagnosis in rural Mozambique. Malar J. 2008;7:33.

32. Oladosu OO, Oyibo WA. Overdiagnosis and Overtreatment of Malaria in Children That Presented with Fever in Lagos, Nigeria. ISRN Infect Dis. 2013:1-6.

33. Reiter P, Fontenille D, Paupy C. Aedes albopictus as an epidemic vector of chikungunya virus: another emerging problem? Lancet Infect Dis. 2006;6(8):463-464.

34. Tsetsarkin KA, Vanlandingham DL, McGee CE, et al. A single mutation in Chikungunya virus affects vector specificity and epidemic potential. PLoS Pathog. 2007;3(12):1895-906.

35. Endy TP, Anderson KB, Nisalak A, et al. Determinants of inapparent and symptomatic dengue infection in a prospective study of primary school children in Kamphaeng Phet, Thailand. PLoS Negl. Trop Dis. 2011;5(3):e975.

36. Sam IC, Kamarulzaman A, Ong GSY, et al. Chikungunya virusassociated death in Malaysia. Trop Biomed. 2010;27(3):343-347.

37. WHO, Dengue guidelines for diagnosis, treatment, prevention and control. New edition, pp.2009;1-160. 